\title{
Prediction of size effects in notched laminates using continuum damage mechanics
}

\author{
P.P. Camanho ${ }^{a}, *$, P. Maimí ${ }^{\text {, }}$, C.G. Dávila ${ }^{c}$ \\ ${ }^{a}$ DEMEGI, Faculdade de Engenharia, Universidade do Porto, Rua Dr. Roberto \\ Frias, 4200-465, Porto, Portugal \\ ${ }^{\mathrm{b}}$ AMADE, University of Girona, Campus Montilivi s/n, Girona, Spain \\ ${ }^{\mathrm{c}}$ NASA Langley Research Center, Hampton, VA, U.S.A.
}

\begin{abstract}
This paper examines the use of a continuum damage model to predict strength and size effects in notched carbon-epoxy laminates. The effects of size and the development of a fracture process zone before final failure are identified in an experimental program. The continuum damage model is described and the resulting predictions of size effects are compared with alternative approaches: the point stress and the inherent flaw models, the Linear-Elastic Fracture Mechanics approach, and the strength of materials approach. The results indicate that the continuum damage model is the most accurate technique to predict size effects in composites. Furthermore, the continuum damage model does not require any calibration and it is applicable to general geometries and boundary conditions.
\end{abstract}

Key words: Size effect, Continuum Damage Mechanics, Fracture Mechanics.

\section{Introduction}

The introduction of advanced composite materials in new applications relies on the development of accurate analytical and computational tools that are able to predict the thermo-mechanical response of composites under general loading conditions and geometries. In the absence of accurate analytical models, the design process has to rely on costly matrices of mechanical tests based on large numbers of test specimens [1] and empirical knockdown factors [2].

* Corresponding author

Email address: pcamanho@fe.up.pt (P.P. Camanho). 
The prediction of ultimate strength remains the main challenge in the simulation of the mechanical response of composite materials [3]. The simulation of size effects on the strength of composites is of particular interest and relevance [4]-[8]: reliable analytical and numerical models must represent the decrease of the ultimate strength when the structural dimensions increase [9].

Size effects in laminated composites occur at different material and structural levels. At the meso-mechanical level, it is observed that the transverse tensile and in-plane shear strengths of a ply constrained by sub-laminates depend on the ply thickness [10]. This size effect is normally called the "in-situ" effect and can be accounted for in the prediction of matrix cracking onset using the "in-situ" strengths in appropriate failure criteria. The "in-situ" strengths can be calculated from analytical closed-form solutions using ply elastic properties and fracture energies [11],[12].

Size effects also occur at the macro-mechanical level. For example, it is shown in [13] that the strength of notched quasi-isotropic composite laminates decreases for increasing notch sizes when thin plies are used. This effect, usually known as the "hole size effect", is caused by the development and propagation of non-critical ply-level damage mechanisms that occur in the vicinity of the hole before the final collapse of the laminate. The exact nature of the non-critical damage mechanisms has been reported by several authors. Using Moiré interferometry in notched $[0 /+45 / 90 /-45]_{s}$ laminates, Mollenhauer et al. [14] observed a strain redistribution as a result of matrix-fiber splitting in the $0^{\circ}$ surface ply and sub-surface ply cracking. Green et al. [4] reported fiber splitting in the $0^{\circ}$ plies, matrix cracking in the off-axis plies, and delamination in $\left[+45_{m} / 90_{m} /-45_{m} / 0_{m}\right]_{n s}$ carbon-epoxy laminates with a central circular hole.

The observed ply-level damage mechanisms can be regarded as a fracture process zone that develops before final failure of the laminate. For very small specimens, the fracture process zone affects the entire width of the laminate. On the other hand, the size of the fracture process zone in large specimens is negligible when compared with the characteristic dimensions of the specimen. The relative dimension of the fracture process zone with respect to the specimen size justifies the different strengths observed in small and large specimens. Therefore, to predict the hole size effect in quasi-brittle materials with general dimensions, methods that account for the energy dissipated by the propagation of non-critical damage mechanisms are required [15].

While the strength of notched multidirectional laminates manufactured using thin plies generally decreases with hole diameter, Green et al. [4] reported an opposite trend for laminates with plies with the same fiber orientation blocked together (ply-level scaling): for a $4 \mathrm{~mm}$ thick $\left[45_{4} / 90_{4} /-45_{4} / 0_{4}\right]_{s}$ carbon fiber reinforced plastic (CFRP) laminate, increasing the hole size from $3.2 \mathrm{~mm}$ to 
$25.4 \mathrm{~mm}$ increased the strength by $51 \%$. This new finding was attributed to the formation of delaminations at the edge of the hole [4]. Ply-blocked specimens exhibit a delamination type of failure, and for small hole diameters the size of the delamination is relatively large and grows unstably.

Green et al. also performed tests on thickness-scaled CFRP laminates [4]. A decrease of the ultimate strength with test specimen thickness was reported for both ply-level and sublaminate-level scaled laminates, where the laminate thickness is increased by increasing the number of sublaminates while keeping the ply thickness constant. When increasing the thickness from $1 \mathrm{~mm}$ to 8 $\mathrm{mm}$, strength reductions of $16.5 \%$ and $64.4 \%$ were measured for the sublaminate level and ply-level scaled specimens, respectively. The strength reduction was attributed to the higher energy release rate at the interfaces of the plylevel scaled specimens, which promotes delamination, and to the higher stress concentration relief that occurs as a result of damage in the surface plies of sublaminate-level scaled specimens.

The calculation of macro-mechanical size effects is often based on semi-empirical methods that require calibration such as the point stress and average stress models proposed by Whitney and Nuismer [16]. The point stress model assumes that final failure occurs when the stress at a characteristic distance from the notch reaches the unnotched strength of the laminate. In the average stress model, it is assumed that final failure occurs when the laminate stress averaged over a characteristic distance is equal to the unnotched strength of the laminate. Modifications of the point stress and average stress models using ply strengths have been proposed to predict the strength of laminates with open and loaded holes [17]-[18]. The advantage of using ply properties rather than laminate properties is that the need to measure laminate strengths for every layup is avoided. However, the measurement of the characteristic distances is still required for each lay-up and geometry [18].

On the other hand, models based on continuum damage mechanics do not require calibration, so they potentially provide the means for a truly predictive methodology for the strength prediction of composite laminates. Continuum damage models are defined in the framework of the thermodynamics of irreversible processes. Generally speaking, the formulation of continuum damage models starts by the definition of a potential (e.g. the complementary free energy) as a function of one or more damage variables that is the basis for establishing the relation between the stress and the strain tensors. It is also required to define the damage activation functions, i.e. the conditions that lead to the onset of inelastic response, and the damage evolution functions. Some of the models proposed in the literature are exclusively based on thermodynamic restrictions of the constitutive model and on some adjusting functions for damage onset and evolution. Other models, besides satisfying the thermodynamic restrictions, are based on the failure mechanisms [19], i.e. the damage 
activation functions are related to the physics of the different failure mechanisms, and the damage variables are related to the orientation of the ply failure planes experimentally observed. Mechanism-based continuum damage models can predict damage onset and the extent and type of non-critical damage mechanisms. Furthermore, continuum damage models that relate the damage variables to the normal components of the stress tensor are able to simulate the effect of crack closure under load reversal cycles. Therefore, such models can be used to predict the strength under non-monotonic loading including load reversals.

The objective of this paper is to investigate the use of a continuum damage model for the prediction of size effects in notched carbon-epoxy laminates loaded in tension. An experimental program is conducted to measure the relevant material properties and to identify size effects occurring in laminates with different hole sizes. The recently proposed continuum damage model is described and analysis of open hole specimens subjected to tension loads are presented. The analyses results are compared with the experimental data and with predictions obtained using a strength of materials approach, LinearElastic Fracture Mechanics, and the point stress model.

\section{Experimental program}

\subsection{Material selection and characterization}

The material selected for the present study is Hexcel's IM7-8552 carbon epoxy unidirectional tape with a nominal ply thickness of $0.131 \mathrm{~mm}$. The material was cured according to the manufacturer's specifications, with temperature stages of $110^{\circ} \mathrm{C}$ for one hour, followed by $180^{\circ} \mathrm{C}$ for two hours. A pressure of 7 bar was applied for the duration of the cure cycle.

The fiber volume fraction was measured using image processing techniques resulting in an average value of 59.1\%. The coefficients of thermal expansion were measured using a dilatometer and the resulting values are $\alpha_{11}=$ $-5.5 \times 10^{-6} /{ }^{\circ} \mathrm{C}$ for the longitudinal direction, and $\alpha_{22}=25.8 \times 10^{-6} /{ }^{\circ} \mathrm{C}$ for the transverse direction. The elastic properties and strengths were measured using ASTM test standards [20]-[22]. Five specimens were used for each test performed.

The mean measured values of the ply elastic properties are shown in Table 1. $E_{1}$ and $E_{2}$ are the longitudinal and transverse Young's modulus respectively, $G_{12}$ is the shear modulus, and $v_{12}$ is the major Poisson's ratio. Table 1 also presents the standard used in each test, the standard deviation (STDV), and 
the coefficient of variation $(\mathrm{CV})$.

[Table 1 about here.]

The measured ply strengths are shown in Table $2 . X_{\mathrm{T}}$ and $Y_{\mathrm{T}}^{\text {ud }}$ are the longitudinal and transverse tensile strengths, respectively. $X_{\mathrm{C}}$ and $Y_{\mathrm{C}}$ are the longitudinal and transverse compressive strengths, respectively. $S_{\mathrm{L}}^{\text {ud }}$ is the inplane shear strength.

[Table 2 about here.]

The values of the transverse tensile strength $\left(Y_{\mathrm{T}}^{\mathrm{ud}}\right)$ and of the in-plane shear strength $\left(S_{\mathrm{L}}^{\text {ud }}\right)$ measured in the test specimens correspond to the strengths of unconstrained unidirectional plies. The transverse tensile and shear strengths of constrained plies (in-situ strengths) are higher than the ones of an unidirectional ply [10] and decrease when increasing the ply thickness. The in-situ strengths are calculated using models previously proposed by the authors, which are based on the mode I fracture toughness, $\mathrm{G}_{2+}$, and on the mode II fracture toughness, $\mathrm{G}_{6}[12]$. These models use the simplifying assumption that the in-situ strengths are not a function of the elastic properties and geometry of the neighboring layers.

To measure the components of the fracture toughness, double cantilever beam (DCB) [23] and 4-point bending end notched flexure (4-ENF) [24] tests were performed. The measured components of the fracture toughness are shown in Table 3.

[Table 3 about here.]

The in-situ strengths are calculated as functions of the fracture toughness and ply elastic properties using the models described in [12] with a shear response factor $\beta=2.98 \times 10^{-8} \mathrm{MPa}^{-3}$. The calculated in-situ strengths are shown in Table 4 .

[Table 4 about here.]

The shear strength in the transverse direction is calculated as [25],[26]:

$$
S_{\mathrm{T}}=Y_{\mathrm{C}} \cos \alpha_{0}\left(\sin \alpha_{0}+\frac{\cos \alpha_{0}}{\tan 2 \alpha_{0}}\right)
$$

where $\alpha_{0}$ is the fracture angle of a ply under pure transverse compression [27]. For a fracture angle $\alpha_{0}=53^{\circ}$, the shear strength in the transverse direction is calculated as $S_{\mathrm{T}}=75.3 \mathrm{MPa}$.

The continuum damage model also requires the fracture energies per unit 
surface for longitudinal failure, $\mathrm{G}_{1+}$ (tension) and $\mathrm{G}_{1-}$ (compression). These energies were measured using the Compact Tension (CT) and Compact Compression (CC) tests in cross-ply laminates proposed by Pinho et al. [28],[29]. The measured fracture energies per unit surface are shown in Table 5.

[Table 5 about here.]

\subsection{Notched laminates}

Tests of notched composite laminates were performed to quantify the size effect and to obtain empirical data to validate the numerical model. Quasi-isotropic laminates were manufactured in Hexcel IM7-8552 CFRP with a stacking sequence of $[90 / 0 / \pm 45]_{3 \mathrm{~s}}$.

The unnotched tensile strength of the laminate, $X_{T}^{L}$, was measured using five test specimens and the average value obtained was 845.1 MPa. The average value of the failure strain, $12900 \mu \varepsilon$, was measured in the five test specimens using strain gages.

The notched test specimens were machined using a procedure that prevents delaminations in the regions close to the insertion point and the exit of the drill bit. Sacrificial frontal and backing plates were used to clamp the specimens during the drilling process. All test specimens were machined to class 1 hole quality used in aerospace [30]. No damage was observed in a sample of test specimens inspected using X-rays.

Specimens with five different hole diameters, $d=2 \mathrm{~mm}, 4 \mathrm{~mm}, 6 \mathrm{~mm}, 8 \mathrm{~mm}, 10$ $\mathrm{mm}$ and with a width-to-diameter ratio $w / d$ equal to 6 were tested in a MTS servo-hydraulic machine following the ASTM D-5766 standard [31] according to the test matrix shown in Table 6. Five specimens were tested for each geometry.

[Table 6 about here.]

The specimens labeled OHT3, OHT6 and OHT9 were instrumented with two strain gages in the positions schematically shown in Figure 1.

[Fig. 1 about here.]

The distances $d_{s}$ shown in Figure 1 are respectively $10.5 \mathrm{~mm}, 13.5 \mathrm{~mm}$, and $12.5 \mathrm{~mm}$ for the test specimens OHT3, OHT6 and OHT9. The specimens OHT10 and OHT11 were not instrumented. Acoustic emission (AE) sensors were used in one test specimen for each size. 
Figure 2 shows the applied load and the cumulative number of AE signals as a function of time for one OHT3 test specimen.

[Fig. 2 about here.]

From the AE signals shown in Figure 2, it can be concluded that non-critical damage mechanisms accumulate well before final failure of the specimen, creating a fracture process zone (FPZ). Similar results are observed in the OHT6 and OHT9 specimens, as well as in other experimental investigations [4],[14].

The remote failure stress is defined using the failure load measured in the tests $(\bar{P})$ and the measured values of the specimen thickness $\left(t_{L}\right)$ and width $(w)$ as: $\bar{\sigma}^{\infty}=\frac{\bar{P}}{w t_{L}}$. The remote failure stresses obtained for the different geometries are summarized in Table 7.

[Table 7 about here.]

The failure mode observed in all specimens is net-section tension, as shown in Figure 3. Figure 4 shows the relation between the remote stress and the strain measured by strain gages SG3 for one test specimen of each of the three different geometries.

[Fig. 3 about here.]

[Fig. 4 about here.]

The experimental results presented in Table 7 clearly identify a size effect: an increase in the hole diameter from $2 \mathrm{~mm}$ to $10 \mathrm{~mm}$ results in a $32.8 \%$ reduction in the strength. The observed size effect is caused by the development of the fracture process zone identified in the AE results, which re-distributes the stresses and dissipates energy. In small specimens, the fracture process zone extends towards the edges of the specimen and the average stress at the fracture plane tends to the unnotched strength of the laminate.

The effect of size on the strength can be explained using a simple example based on the cohesive crack model, which is well-suited to simulate fracture of quasi-brittle materials [32]. Consider that the fracture process zone is represented by a cohesive crack with the simple constitutive relation shown in Figure 5 a).

[Fig. 5 about here.]

The cohesive constitutive model relates the laminate cohesive stress, $\sigma$, to the crack opening, $w$, and must satisfy the following condition: $\int_{0}^{\infty} \sigma(w) d w=G_{C}$. Structural collapse occurs when a point along the fracture plane reaches the critical opening, $w_{c}$, and the corresponding length of the fracture process zone 
can be estimated using the Irwin model as $l_{\mathrm{FPZ}} \approx \frac{E G_{C}}{\pi\left(X_{T}^{L}\right)^{2}}[33]-[34]$.

Based on the constitutive law shown in Figure 5 a), it is possible to schematically represent the stress distribution at failure along the fracture planes of specimens with different sizes, as shown in Figure $5 \mathrm{~b}$ ). It is observed that in small specimens the fracture process zone extends towards the edges, whereas in large specimens the fracture process zone is confined to the vicinity of the hole. As a consequence, the average stress acting on the fracture plane, and hence the strength, are larger for small specimens.

\section{Simulation of the effect of size on strength}

Strength prediction methods uniquely based on stress or strain failure criteria are unable to predict the size effects observed in notched specimens. Consider for example a calculation of the final failure of a specimen with a central hole using the value of the longitudinal stress in the fiber direction (maximum stress criterion). The distribution of the longitudinal stress in the critical plies, the $0^{\circ}$ plies along the fracture plane, defined by $\theta=90^{\circ}$ in Figure 1, can be calculated using an approximate closed-form solution as [35]:

$$
\sigma_{11}=\sigma_{x x}(0, y)\left(\bar{Q}_{11} a_{11}^{*}+\bar{Q}_{12} a_{12}^{*}\right)
$$

where $a_{i j}^{*}$ are the components of the laminate compliance matrix defined as [36]:

$$
\left[a^{*}\right]=t_{L}[A]^{-1}
$$

where the matrix $[A]$ relates the in-plane forces per unit length to the midplane strains. $\bar{Q}_{i j}$ are the components of the plane stress transformed reduced stiffness matrix of the $0^{\circ}$ plies [18], and $t_{L}$ is the thickness of the laminate.

The through-the-thickness averaged normal stress in the fracture plane for a quasi-isotropic laminate is calculated by Tan [35] as:

$$
\sigma_{x x}(0, y)=\frac{2+(1-d / w)^{3}}{6(1-d / w)}\left[2+\left(\frac{d}{2 y}\right)^{2}+3\left(\frac{d}{2 y}\right)^{4}\right] \sigma_{x x}^{\infty}, y \geq d / 2
$$

where $\sigma_{x x}^{\infty}$ is the remote tensile stress. 
From equations (2) and (4) it is clear that for the same material and stacking sequence the stress concentration factor, and hence the maximum longitudinal stress in the $0^{\circ}$ ply, depends on the ratio between the specimen hole diameter and width. Applying the maximum stress criterion and using equations (2) and (4):

$$
\frac{\sigma_{11}}{X_{T}}=1 \Rightarrow \bar{\sigma}^{\infty}=\frac{(1-d / w) X_{T}}{\left[2+(1-d / w)^{3}\right]\left(\bar{Q}_{11} a_{11}^{*}+\bar{Q}_{12} a_{12}^{*}\right)}
$$

Equation (5) demonstrates that the application of the maximum stress criterion results in the same strength prediction for different hole diameters when the $d / w$ ratio is held constant. The lack of size effect on the predicted strength clearly contradicts the experimental observations.

\subsection{Linear-Elastic Fracture Mechanics}

There are two approaches that can be used with Linear Elastic Fracture Mechanics (LEFM) to calculate the effect of size on the strength of notched composite laminates. In the first approach, it is assumed that the length $a$ of a pre-existing crack in the laminate is scaled in the same proportion of the hole diameter and specimen width and that the critical value of the laminate's stress intensity factor, $K_{I c}$, is independent of the crack length. Consider two specimens with hole diameters $d_{1}$ and $d_{2}$. The stress intensity factor at failure is:

$$
K_{I c}=\bar{\sigma}_{1}^{\infty} F\left(\frac{w_{1}}{d_{1}}, \frac{a_{1}}{d_{1}}\right) \sqrt{\pi a_{1}}=\bar{\sigma}_{2}^{\infty} F\left(\frac{w_{2}}{d_{2}}, \frac{a_{2}}{d_{2}}\right) \sqrt{\pi a_{2}}
$$

Taking into account the fact that the crack length is proportional to the hole diameter and that the finite width correction factors, $F(w / d, a / d)$, are equal for scaled geometries, the failure stress of a specimen with a hole diameter $d_{2}$ can be calculated from the failure stress of the specimen with a hole diameter $d_{1}$ :

$$
\bar{\sigma}_{2}^{\infty}=\bar{\sigma}_{1}^{\infty} \sqrt{\frac{d_{1}}{d_{2}}}
$$

The second approach to predict size effects using LEFM is the inherent flaw model (IFM) proposed by Waddoups et al. [13]. It is considered that the noncritical damage mechanisms occurring before ultimate failure of a composite 
laminate can be lumped into a constant "region of intense energy", or "inherent flaw", of length $a$. The critical value of the stress intensity factor of a plate with a hole of radius $R$ is given by:

$$
K_{I c}=f(a, R) \bar{\sigma}^{\infty} \sqrt{\pi a}
$$

where $f(a, R)$ is Bowie's solution for the calculation of the stress intensity factor of two cracks emanating from a circular hole, given as [37]-[38]:

$$
f(a, R)=0.5\left(3-\frac{a}{d / 2+a}\right)\left[1+1.243\left(1-\frac{a}{d / 2+a}\right)^{3}\right]
$$

Waddoups et al. [13] considered that the strength of an unnotched specimen can be predicted by taking into account that the hole radius tends to zero, in which case the function $f(a, R)$ tends to one, leaving:

$$
K_{I c}=X_{T}^{L} \sqrt{\pi a}
$$

where $X_{T}^{L}$ is the tensile strength of the unnotched laminate.

From (8) and (10), the equation proposed by Waddoups et al. [13] is obtained:

$$
\bar{\sigma}^{\infty}=X_{T}^{L} / f(a, R)
$$

The strength of the laminate containing an open-hole is predicted using two parameters: the length of the inherent flaw, $a$, that needs to be calculated from a baseline specimen, and the unnotched tensile strength of the laminate, $X_{T}^{L}$.

\subsection{Point-stress model}

The point-stress model (PSM) proposed by Whitney and Nuismer [16], considers that ultimate failure occurs when the stress at a given distance from the hole boundary, $r_{o t}$, reaches the unnotched strength of the laminate, $X_{T}^{L}$. An alternative version of the point stress model uses the ply stresses and strengths, so that it is not necessary to measure the strength for every different laminate.

Using equations (2) and (4), the strength predicted using the PSM is: 
$\bar{\sigma}^{\infty}=X_{T}\left\{\frac{2+\left(1-\frac{d}{w}\right)^{3}}{6\left(1-\frac{d}{w}\right)}\left[2+\left(\frac{d}{d+2 r_{o t}}\right)^{2}+3\left(\frac{d}{d+2 r_{o t}}\right)^{4}\right]\left(\bar{Q}_{11} a_{11}^{*}+\bar{Q}_{12} a_{12}^{*}\right)\right\}^{-1}$

Failure is predicted using two parameters: the characteristic distance in tension $r_{o t}$, and the longitudinal tensile strength of the ply, $X_{T}$.

\subsection{Continuum damage model}

Continuum Damage Mechanics is a methodology well suited for the simulation of damage evolution and ultimate failure of composites under general loads and boundary conditions for which no analytical solution is available. The continuum damage model used here is based on previous work by the authors [19],[39],[40]. The main aspects of the continuum damage model are presented in the following sections. The full details of the model can be found in references [19],[39] and [40].

\subsubsection{Constitutive model}

The proposed definition for the complementary free energy density of a ply is:

$$
\begin{aligned}
G= & \frac{\sigma_{11}^{2}}{2\left(1-\mathrm{d}_{1}\right) E_{1}}+\frac{\sigma_{22}^{2}}{2\left(1-\mathrm{d}_{2}\right) E_{2}}-\frac{\nu_{12}}{E_{1}} \sigma_{11} \sigma_{22}+\frac{\sigma_{12}^{2}}{2\left(1-\mathrm{d}_{6}\right) G_{12}}+ \\
& +\left(\alpha_{11} \sigma_{11}+\alpha_{22} \sigma_{22}\right) \Delta T+\left(\beta_{11} \sigma_{11}+\beta_{22} \sigma_{22}\right) \Delta M
\end{aligned}
$$

where the damage variable $d_{1}$ is associated with longitudinal (fiber) failure, $\mathrm{d}_{2}$ is the damage variable associated with transverse matrix cracking, and $\mathrm{d}_{6}$ is the damage variable associated with longitudinal and transverse cracks. $\beta_{11}$ and $\beta_{22}$ are the coefficients of hygroscopic expansion in the longitudinal and transverse directions, respectively. $\Delta T$ and $\Delta M$ are the differences of temperature and moisture content with respect to the corresponding reference values. The coefficients of thermal expansion of a ply are also affected by the failure mechanisms. The exact dependence of the coefficients of thermal expansion with damage can be obtained for simple laminates in the absence of stress gradients [41]. These conditions are not met by the laminate under investigation here and the effects of damage on the coefficients of thermal expansion are neglected.

The strain tensor is equal to the derivative of the complementary free energy 
density with respect to the stress tensor:

$$
\varepsilon=\frac{\partial G}{\partial \sigma}=\mathbf{H}: \sigma+\alpha \Delta T+\beta \Delta M
$$

The lamina compliance tensor can be represented as:

$$
\mathbf{H}=\frac{\partial^{2} G}{\partial \sigma^{2}}=\left[\begin{array}{ccc}
\frac{1}{\left(1-\mathrm{d}_{1}\right) E_{1}} & -\frac{v_{12}}{E_{1}} & 0 \\
-\frac{v_{12}}{E_{1}} & \frac{1}{\left(1-\mathrm{d}_{2}\right) E_{2}} & 0 \\
0 & 0 & \frac{1}{\left(1-\mathrm{d}_{6}\right) G_{12}}
\end{array}\right]
$$

The closure of transverse cracks under load reversal is taken into account by defining four damage variables associated with longitudinal and transverse damage. To distinguish between the active and the passive damage variables, it is necessary to define the longitudinal and transverse damage modes as follows:

$$
\begin{aligned}
& \mathrm{d}_{1}=\mathrm{d}_{1+} \frac{\left\langle\sigma_{11}\right\rangle}{\left|\sigma_{11}\right|}+\mathrm{d}_{1-} \frac{\left\langle-\sigma_{11}\right\rangle}{\left|\sigma_{11}\right|} \\
& \mathrm{d}_{2}=\mathrm{d}_{2+} \frac{\left\langle\sigma_{22}\right\rangle}{\left|\sigma_{22}\right|}+\mathrm{d}_{2-} \frac{\left\langle-\sigma_{22}\right\rangle}{\left|\sigma_{22}\right|}
\end{aligned}
$$

where $\langle x\rangle$ is the McCauley operator defined as $\langle x\rangle:=(x+|x|) / 2$.

\subsubsection{Damage activation functions}

The determination of the domain of elastic response under complex stress states is an essential component of an accurate damage model. It is assumed that the elastic domain is enclosed by four surfaces, each of them accounting for one damage mechanism: longitudinal and transverse fracture under tension and compression. Those surfaces are formulated by the damage activation functions based on the LaRC04 failure criteria [26].

The four damage activation functions, $F_{N}$, associated with damage in the longitudinal $(N=1+, 1-)$ and transverse $(N=2+, 2-)$ directions represented in Figure 6, are defined as: 


$$
\begin{aligned}
& F_{1+}=\phi_{1+}-r_{1+} \leq 0 ; F_{1-}=\phi_{1-}-r_{1-} \leq 0 \\
& F_{2+}=\phi_{2+}-r_{2+} \leq 0 ; F_{2-}=\phi_{2-}-r_{2-} \leq 0
\end{aligned}
$$

where the loading functions $\phi_{N}(N=1+, 1-, 2+, 2-)$ depend on the strain tensor and material constants (elastic and strength properties). The elastic domain thresholds $r_{N}(N=1+, 1-, 2+, 2-)$ take an initial value of 1 when the material is undamaged, and they increase with damage. The elastic domain thresholds are related to the damage variables $\mathrm{d}_{M}(M=1+, 1-, 2+, 2-, 6)$ by the damage evolution laws.

[Fig. 6 about here.]

The current values of the elastic domain thresholds $r_{N}$ are obtained using the loading functions $\phi_{N}$ according to the following equations [19],[39],[40]:

$$
\begin{aligned}
& r_{1+}=\max \left\{1, \max _{s=0, t}\left\{\phi_{1+}^{s}\right\}, \max _{s=0, t}\left\{\phi_{1-}^{s}\right\}\right\} \\
& r_{1-}=\max \left\{1, \max _{s=0, t}\left\{\phi_{1-}^{s}\right\}\right\} \\
& r_{2+}=\max \left\{1, \max _{s=0, t}\left\{\phi_{2-}^{s}\right\}, \max _{s=0, t}\left\{\phi_{2+}^{s}\right\}\right\} \\
& r_{2-}=\max \left\{1, \max _{s=0, t}\left\{\phi_{2-}^{s}\right\}\right\}
\end{aligned}
$$

\section{Longitudinal tensile fracture}

The LaRC04 criterion for fiber tension is defined as:

$$
\phi_{1+}=\frac{E_{1}}{X_{T}} \varepsilon_{11}=\frac{\tilde{\sigma}_{11}-v_{12} \tilde{\sigma}_{22}}{X_{T}}
$$

where the effective stress tensor $\tilde{\sigma}$ is computed as $\tilde{\sigma}=\mathbf{H}_{\mathbf{0}}{ }^{-1}: \varepsilon \cdot \mathbf{H}_{\mathbf{0}}$ is the undamaged compliance tensor.

\section{Longitudinal compressive fracture}

The damage activation function used to predict damage under longitudinal compression $\left(\tilde{\sigma}_{11}<0\right)$ and in-plane shear (fiber kinking) is established as a function of the components of the stress tensor $\tilde{\sigma}^{(m)}$ in a coordinate system $(m)$ representing the fiber misalignment: 


$$
\phi_{1-}=\frac{\left\langle\left|\tilde{\sigma}_{12}^{m}\right|+\eta^{L} \tilde{\sigma}_{22}^{m}\right\rangle}{S_{L}}
$$

where the coefficient of longitudinal influence can be approximated as [26]:

$$
\eta^{L} \approx-\frac{S_{L} \cos \left(2 \alpha_{0}\right)}{Y_{C} \cos ^{2} \alpha_{0}}
$$

with $\alpha_{0}=53^{\circ}$ [27]. The components of the effective stress tensor in the coordinate system associated with the rotation of the fibers are calculated as:

$$
\begin{aligned}
& \tilde{\sigma}_{22}^{m}=\tilde{\sigma}_{11} \sin ^{2} \varphi^{C}+\tilde{\sigma}_{22} \cos ^{2} \varphi^{C}-2\left|\tilde{\sigma}_{12}\right| \sin \varphi^{C} \cos \varphi^{C} \\
& \tilde{\sigma}_{12}^{m}=\left(\tilde{\sigma}_{22}-\tilde{\sigma}_{11}\right) \sin \varphi^{C} \cos \varphi^{C}+\left|\tilde{\sigma}_{12}\right|\left(\cos ^{2} \varphi^{C}-\sin ^{2} \varphi^{C}\right)
\end{aligned}
$$

The misalignment angle $\left(\varphi^{C}\right)$ is determined using standard shear and longitudinal compression strengths, $S_{L}$ and $X_{C}$, respectively [26]:

$$
\varphi^{C}=\arctan \left(\frac{1-\sqrt{1-4\left(\frac{S_{L}}{X_{C}}+\eta^{L}\right) \frac{S_{L}}{X_{C}}}}{2\left(\frac{S_{L}}{X_{C}}+\eta^{L}\right)}\right)
$$

\section{Transverse fracture perpendicular to the mid-plane of the ply}

Transverse matrix cracks perpendicular to the mid-plane of the ply, i.e. with $\alpha_{0}=0^{\circ}$, are created by a combination of in-plane shear stresses and transverse tensile stresses, or in-plane shear stresses and small transverse compressive stresses. These conditions are represented by the following failure criteria:

$$
\phi_{2+}=\left\{\begin{array}{cl}
\sqrt{(1-g) \frac{\tilde{\sigma}_{22}}{Y_{T}}+g\left(\frac{\tilde{\sigma}_{22}}{Y_{T}}\right)^{2}+\left(\frac{\tilde{\sigma}_{12}}{S_{L}}\right)^{2}} & \text { if } \tilde{\sigma}_{22} \geq 0 \\
\frac{1}{S_{L}}\left\langle\left|\tilde{\sigma}_{12}\right|+\eta^{L} \tilde{\sigma}_{22}\right\rangle & \text { if } \tilde{\sigma}_{22}<0
\end{array}\right.
$$

where $g$ is the fracture toughness ratio defined as: $g=\frac{\mathrm{G}_{2+}}{\mathrm{G}_{6}}$.

\section{Transverse compressive fracture}

The matrix failure criterion for transverse compressive stresses consists of a quadratic interaction between the effective shear stresses acting on the fracture plane: 


$$
\phi_{2-}=\sqrt{\left(\frac{\tilde{\tau}_{\text {eff }}^{T}}{S_{T}}\right)^{2}+\left(\frac{\tilde{\tau}_{\text {eff }}^{L}}{S_{L}}\right)^{2}} \text { if } \tilde{\sigma}_{22}<0
$$

where the effective stresses $\tilde{\tau}_{\text {eff }}^{T}$ and $\tilde{\tau}_{\text {eff }}^{L}$ are computed as [26]:

$$
\begin{aligned}
& \tilde{\tau}_{\text {eff }}^{T}=\left\langle-\tilde{\sigma}_{22} \cos \left(\alpha_{0}\right)\left(\sin \left(\alpha_{0}\right)-\eta^{T} \cos \left(\alpha_{0}\right) \cos \left(\theta_{s}\right)\right)\right\rangle \\
& \tilde{\tau}_{\text {eff }}^{L}=\left\langle\cos \left(\alpha_{0}\right)\left(\left|\tilde{\sigma}_{12}\right|+\eta^{L} \tilde{\sigma}_{22} \cos \left(\alpha_{0}\right) \sin \left(\theta_{s}\right)\right)\right\rangle
\end{aligned}
$$

with $\eta^{T}=\frac{-1}{\tan \left(2 \alpha_{0}\right)}$ and $\theta_{s}=\arctan \left(\frac{-\left|\tilde{\sigma}_{12}\right|}{\tilde{\sigma}_{22} \sin \left(\alpha_{0}\right)}\right)$.

\subsubsection{Damage evolution laws and numerical implementation}

Strain-softening constitutive models that do not take into account the finite element discretization produce results that are mesh-dependent, i.e. the solution is non-objective with respect to the mesh refinement and the computed energy dissipated decreases with a reduction of the element size [42]-[43]. An effective solution to assure objective solutions consists of using a characteristic length of the finite elements $\left(l^{*}\right)$ in the definition of the constitutive model [42]. As schematically shown in Figure 7, the post-peak response of the material is scaled as a function of the element size to keep the computed energy dissipation independent of the size of the element, and equal to the material fracture energy.

[Fig. 7 about here.]

The energetic regularization of the model proposed requires the fracture energies associated with the four fracture planes shown in Figure 6. These fracture energies were measured in the experimental program and are used in the damage evolution laws.

The exponential damage evolution laws proposed by the authors [19],[39],[44] are expressed in the following general form:

$$
\mathrm{d}_{M}=1-\frac{1}{f_{N}\left(r_{N}\right)} \exp \left\{A_{M}\left[1-f_{N}\left(r_{N}\right)\right]\right\} f\left(r_{K}\right)
$$

where the function $f_{N}\left(r_{N}\right)$ is selected to force the softening of the constitutive relation and it is taken as being independent of the material. The term $f\left(r_{K}\right)$ represents the coupling factor between damage laws and elastic threshold domains. The specific damage evolution laws for each damage variable are presented in [19], [39]-[44]. 
The regularization of the energy dissipated is performed by integrating the rate of energy dissipation for each failure mode. The energy dissipated in each failure mode must be independent of the element size, and must be equal to the fracture energy measured in the experiments:

$$
\int_{1}^{\infty} \frac{\partial G}{\partial \mathrm{d}_{M}} \frac{\partial \mathrm{d}_{M}}{\partial r_{M}} d r_{M}=\frac{G_{M}}{l^{*}}, M=1+, 1-, 2+, 2-, 6
$$

Using (27) in (28), it is possible to numerically integrate the resulting equation and calculate the parameters $A_{M}$ that assure a mesh-independent solution [19].

The constitutive model was implemented in the ABAQUS Finite Element (FE) code [45] as a user-written UMAT subroutine.

\subsubsection{Mesh objectivity and unidirectional notched specimen}

The mesh objectivity of the model proposed is illustrated by simulating the response of a notched $[90]_{24} \mathrm{CFRP}$ laminate loaded in tension. The specimen simulated is $150 \mathrm{~mm}$ long, $12 \mathrm{~mm}$ wide, $3 \mathrm{~mm}$ thick, and contains a central circular notch with a diameter of $6 \mathrm{~mm}$. The properties used are reported in Tables 1 to 3 .

Two FE models with different mesh refinements and using the damage model outlined in the previous sections were created. Models 1 and 2 use, respectively, 6 and 20 elements along the fracture plane. Only one-half of the specimen width is modeled. The details of the two meshes are shown in Figure 8.

[Fig. 8 about here.]

Figure 9 shows the load-displacement relation predicted using the constitutive model proposed. It is observed that the solution is independent of the mesh refinement.

[Fig. 9 about here.]

In order to demonstrate the error introduced by not accounting for element size, two analyses with different levels of mesh refinement were also conducted with a constitutive model that is not adjusted using equations (28). Instead, a constant softening parameter $A_{2+}=1.5$ is used, independently of the mesh refinement. The load-displacement relation predicted by this model is shown in Figure 10. It is clear from this figure that the maximum load and energy dissipation predicted are a function of the refinement of the mesh.

[Fig. 10 about here.] 


\subsubsection{Quasi-isotropic open hole tension specimens}

Finite element models of all OHT specimens shown in the test matrix presented in Section 2 were created using ABAQUS [45] four-node S4 shell elements. The difference between the working and reference temperatures used to calculate the residual thermal stresses was $-155^{\circ} \mathrm{C}$. An implicit dynamic analysis was subsequently performed, and the loading rate used in the experiments, $2 \mathrm{~mm} / \mathrm{min}$, was also applied to the numerical models. The use of an implicit dynamic finite element model enables the prediction of the load drop that occurs when the specimens fail catastrophically. The material properties used are presented in Tables 1 to 5 .

Delamination is not simulated by the model. As explained by Green at al. [4], delamination is the driving failure mechanism for ply-blocked laminates, but not for sublaminate-level scaled laminates, such as those used in this work. The simulation of delamination is required for ply-blocked laminates, and can be performed using cohesive elements connecting several shell elements that represent the layers [46].

The models simulate the fracture process from the onset of damage up to structural collapse. Figure 11 shows the evolution of fiber fracture predicted in the top $0^{\circ}$ ply, as well the plane of localized deformation (fracture plane) for specimen configuration OHT9.

[Fig. 11 about here.]

Figure 12 shows the relation between the applied remote stress and the longitudinal deformation measured using the strain gages and the corresponding numerical predictions in the specimen OHT6. The numerical results correspond to the averaged strain calculated in the group of elements whose position and total area correspond approximately to the area where the strain gages were bonded to the specimen. The location of the different strain gages is shown in Figure 1.

[Fig. 12 about here.]

The remote failure stresses measured in the experimental program and predicted by the numerical model are shown in Table 8 .

[Table 8 about here.]

From the comparison between the experimental and numerical results, both in terms of stress-strain relations and failure stresses, it can be concluded that the model is capable of predicting with good accuracy the response of all OHT specimens that were tested. 


\subsection{Comparison of approaches}

The four methods previously described, i.e. strength of materials, LEFMscaled, LEFM-inherent flaw model, point stress model, and continuum damage model were applied to predict the size effect for the specimens described in Section 2.2.

Equation (7) provides the LEFM-scaled prediction for the notched strength of the laminate when all the in-plane dimensions are scaled. The average failure stress measured in the specimens with a hole diameter of $6 \mathrm{~mm}$ was used in the LEFM model to predict the strength of the specimens with different geometries.

Equation (11) provides the LEFM-inherent flaw model prediction of the notched strength. The specimen with a $6 \mathrm{~mm}$ hole diameter is used to calculate the length of the inherent flaw. Using the measured mean failure stress in equation (11), the length of the inherent flaw is calculated as $a=1.28 \mathrm{~mm}$.

The point-stress prediction of the size effect is performed using equation (12). The characteristic distance of $0.75 \mathrm{~mm}$ was obtained by using the measured mean failure stress in the specimen with a $6 \mathrm{~mm}$ hole diameter. This value of the characteristic distance is used to predict the strength of the other specimens.

The predictions of the normalized strength as a function of the hole diameter obtained using the different models are shown in Figure 13.

[Fig. 13 about here.]

It can be observed that both the point stress and LEFM-IFM models can predict with reasonable accuracy the size effect law of notched composite laminates. The point stress and inherent flaw models are particularly accurate for specimens with hole diameters close to the diameter used to calculate the characteristic distance (PSM) and the length of the inherent flaw. For specimens with small hole diameters, the predictions lose accuracy. Therefore, to accurately predict the notched strength of laminates these models require the calculation of the characteristic distance and length of inherent flaw for different geometries, and the definition of an extrapolation procedure to define the values of these parameters for other geometries [18]. It should also be noted that the basic equation used in the inherent flaw model, equation (11), is only valid when finite width effects are negligible, which is the case of the specimens tested. For smaller ratios between the specimen width and hole diameter, the inherent flaw model should be modified.

The continuum damage model can predict the size effect law observed in the 
experiments, especially for specimens with hole diameters smaller than $6 \mathrm{~mm}$. Unlike the point stress and inherent flaw models, the continuum damage model does not require any adjustment parameter and only uses material properties that are measured at the ply level as well as the fracture energies.

Figure 13 indicates that the use of the LEFM-scaled model results in accurate predictions for hole sizes between $6 \mathrm{~mm}$ and $10 \mathrm{~mm}$. However, the strength is overpredicted for small hole diameters. For small specimens, the damaged region in the vicinity of the hole cannot be considered to be negligible when compared with the characteristic dimensions of the specimen, and LEFM is not applicable.

LEFM-scaled predictions are also inaccurate for large specimens because the notched strengths of those specimens tend to a constant value [4]. Bažant [15] relates this asymptotic structural response to the invariance of the size of the fracture process zone when the characteristic dimensions of large specimens are increased. It should also be noted that the LEFM predictions based on scaled specimens always result in a line with a $-1 / 2$ slope that passes through the baseline point (Figure 13). This means that the use of a small hole diameter as the baseline point would result in severe underpredictions of the notched strength of larger specimens.

The maximum stress criterion for longitudinal failure is unable to predict size effects and always underpredicts the strength of notched laminates. For a hole diameter of $2 \mathrm{~mm}$, the application of the maximum stress criterion results in an error of $-49.1 \%$. The error associated with the strength of materials approach is even larger when using a failure criterion for transverse (matrix) cracking, which occurs before fiber fracture, or failure criteria that are unable to distinguish fiber and matrix failure modes.

\section{Conclusions}

The size effect in notched IM7-8552 CFRP was identified and quantified in an experimental program. The acoustic emission results show that final fracture is preceded by a process of accumulation of non-critical damage mechanics.

By comparing the experimental data with the different models that are commonly used for the strength prediction of composites, it can be concluded that fiber-based failure criteria (strength of materials approach) cannot predict size effects. In addition, the strength of materials approach always underpredicts the strength of notched composites, with errors as high as $-49.1 \%$ for a specimen with a $2 \mathrm{~mm}$ hole diameter. 
The Linear Elastic Fracture Mechanics approach using a hole diameter of $6 \mathrm{~mm}$ for calibration predicts the size effect accurately for specimens with hole diameters between $6 \mathrm{~mm}$ and $10 \mathrm{~mm}$. However, Linear Elastic Fracture Mechanics should not be used for the strength prediction of specimens with hole diameters equal to or less than $2 \mathrm{~mm}$, or for larger specimens whose failure stresses tend to a constant value.

The point stress and inherent flaw models are simple approaches that do not require complex FE implementations yet provide reasonable predictions for the range of hole diameters tested. However, the accuracy of these models relies upon the measurement of the characteristic distance and length of the inherent flaw for each lay-up and stacking sequence.

For the problems selected, the continuum damage model proposed predicts with good accuracy hole size effects in composite laminates subjected to tension. The model requires material properties that are measured at the ply level and fracture energies that are measured using both standard test methods and novel compact tension and compact compression test methods. The continuum damage models provides not only the final failure load, but also information concerning the integrity of the material during the load history. Furthermore, the finite element-based damage model can be applied to structures and components of arbitrary configurations where analytical solutions could not be developed.

\section{Acknowledgements}

The financial support of the Portuguese Foundation for Science and Technology (FCT) under the project PDCTE/50354/EME/2003 is acknowledged by the first author. Effort sponsored by the Air Force Office of Scientific Research, Air Force Material Command, USAF, under grant number FA8655-06-1-3072. The U.S. Government is authorized to reproduce and distribute reprints for Governmental purposed notwithstanding any copyright notation thereon.

\section{References}

[1] MIL-HDBK-17, Military Handbook, Polymer Matrix Composites. U.S. Department of Defense. 1994.

[2] Going to extremes: meeting the emerging demand for durable polymer matrix composites, National Research Council, The National Academies Press, Washington, D.C., 2006.

[3] Hinton, M.J. and Soden, P.D. Predicting failure in composite laminates: the background to the exercise. Composites Science and Technology. 1998; 58:10011010. 
[4] Green, B.G., Wisnom, M.R. and Hallet, S.R. An experimental investigation into the tensile strength scaling of notched composites. Composites-Part A. 2007; $38: 867-878$.

[5] Bažant, Z.P., Daniel, I.M. and Li, Z. Size effect and fracture characteristics of composite laminates. Journal of Engineering Materials and Technology. 1996; 118:317-323.

[6] Wisnom, M.R. Size effects in the testing of fibre-reinforced composites. Composites Science and Technology. 1999; 59:1937-1957.

[7] Dvorak, G.J. and Suvorov, A.P. Size effect in fracture of unidirectional composite plates. International Journal of Fracture. 1999; 95:89-101.

[8] Bažant, Z.P., Zhou, Y., Novák, D. and Daniel, I.M. Size Effect on Flexural Strength of Fiber-Composite Laminates. Journal of Engineering Materials and Technology. 2004; 126:29-37.

[9] Bažant, Z.P. Size effect. International Journal of Solids and Structures. 2000; 37:69-80.

[10] Parvizi, A., Garrett, K. and Bailey J. Constrained cracking in glass fibrereinforced epoxy cross-ply laminates, Journal of Material Science. 1978; 13:195201.

[11] Dvorak, G.J. and Laws, N. Analysis of first ply failure in composite laminates. Engineering Fracture Mechanics. 1986; 25:763-770.

[12] Camanho, P.P., Dávila, C.G., Pinho, S.T., Iannucci, L. and Robinson, P. Prediction of in-situ strengths and matrix cracking in composites under transverse tension and in-plane shear, Composites-Part A. 2006; 37:165-176.

[13] Waddoups, M.E.; Eisenmann, J.R. and Kaminski, B.E. Macroscopic fracture mechanics of advanced composite materials. Journal of Composite Materials. $1971 ; 5: 446-454$.

[14] Mollenhauer, D., Iarve, E.V., Kim, R. and Langley, B. Examination of ply cracking in composite laminates with open holes: a Moiré interferomic and numerical study. Composites-Part A. 2006; 37:282-294.

[15] Bažant, Z.P. and Chen, E.P. Scaling of structural failure. Report SAND96-2948, Sandia National Laboratories, Albuquerque, New Mexico, 1996.

[16] Whitney, J.M. and Nuismer, R.J. Stress fracture criteria for laminated composites containing stress concentrations, Journal of Composite Materials. 1974; 8:253-265.

[17] Chang, F.K., Scott, R.A. and Springer, G.S. Strength of mechanically fastened composite joints, Journal of Composite Materials. 1982; 16:470-494.

[18] Camanho, P.P. and Lambert, M., A design methodology for mechanically fastened joints in laminated composite materials. Composites Science and Technology. 2006; 66:3004-3020, 2006. 
[19] Maimí, P., Camanho, P.P., Mayugo, J.A. and Dávila C.G. A thermodynamically consistent damage model for advanced composites. NASA Technical Memorandum 214282. National Aeronautics and Space Administration, 2006.

[20] Standard test method for tensile properties of polymer matrix composite materials, ASTM D 3039/D 3039M-00, American Society for Testing and Materials (ASTM), West Conshohocken, PA, U.S.A.

[21] Standard test method for compressive properties of unidirectional or cross-ply fiber-resin composites, ASTM D 3410-87, American Society for Testing and Materials (ASTM), West Conshohocken, PA, U.S.A.

[22] Standard test method for in-plane shear response of polymer matrix composite materials by test of a $\pm 45^{\circ}$ laminate, ASTM D 3518/3518M-94, American Society for Testing and Materials (ASTM), West Conshohocken, PA, U.S.A.

[23] Standard test methods for mode I interlaminar fracture toughness of unidirectional fiber-reinforced polymer matrix composites, ASTM D 5528-01, American Society for Testing and Materials (ASTM), West Conshohocken, PA, U.S.A.

[24] Martin, R., Elms, T. and Bowron, S. Characterization of mode II delamination using the 4ENF. Proceedings of the 4th European Conference on Composites: Testing and Standardisation, Lisbon, 1998.

[25] Dávila, C.G., Camanho, P.P. and Rose, C.A., Failure criteria for FRP laminates. Journal of Composite Materials. 2005; 39:323-345.

[26] Pinho, S.T., Dávila, C.G., Camanho, P.P., Iannucci, L. and Robinson, P. Failure models and criteria for FRP under in-plane or three-dimensional stress states including shear non-linearity, NASA Technical Memorandum 213530, National Aeronautics and Space Administration, U.S.A., 2005.

[27] Puck, A. and Schürmann, H. Failure analysis of FRP laminates by means of physically based phenomenological models. Composites Science and Technology. 1998; 58:1045-1067.

[28] Pinho, S.T., Modelling failure of laminated composites using physically-based failure models. Ph.D Thesis, Department of Aeronautics, Imperial College London, U.K. (2005).

[29] Pinho, S.T., Robinson, P. and Iannucci, L., Fracture toughness of the tensile and compressive fibre failure modes in laminated composites, Composites Science and Technology. 2006; 66: 2069-2079.

[30] Sawicki, A.J. and Minguet, P.J. The influence of fastener clearance upon the failure of compression-loaded composite bolted joints. Composite Structures: Theory and Practice, ASTM STP 1383, American Society for Testing and Materials, 293-308, 2000.

[31] Open hole tensile strength of polymer composite laminates, ASTM D 5766/D 5766M-02a, American Society for Testing and Materials (ASTM), West Conshohocken, PA, U.S.A. 
[32] Turon, A., Camanho, P.P., Costa, J. and Dávila, C.G. A damage model for the simulation of delamination in advanced composites under variable-mode loading. Mechanics of Materials. 2006; 38:1072-1089.

[33] Irwin, G.R., Plastic zone near a crack and fracture toughness. Proceedings of the Seventh Segamore Ordenance Materials Conference, 63-78, New York, 1960.

[34] Turon, A., Dávila. C.G., Camanho, P.P. and Costa, J. An engineering solution for using coarse meshes in the simulation of delamination with cohesive zone models, NASA Technical Memorandum 213547, National Aeronautics and Space Administration, U.S.A., 2005.

[35] Tan, S.C. Stress concentrations in laminated composites, Technomic Publishing Company, Inc., 2004.

[36] Herakovich, C.T. Mechanics of fibrous composites, John Wiley and Sons, Inc., 1998.

[37] Bowie, O.L. Analysis of an infinite plate containing radial cracks, originating at the boundaries of an internal circular hole. Journal of Mathematics and Physics. 1956; 35:60-71.

[38] Tada, H., Paris, P. and Irwin, G.R., The stress analysis of cracks handbook, The American Society of Mechanical Engineers, New York, 2000.

[39] Maimí, P., Camanho, P.P., Mayugo, J.A. and Dávila, C.G. A continuum damage model for composite laminates: part I - constitutive model. Mechanics of Materials. 2006; submitted for publication.

[40] Maimí, P., Camanho, P.P., Mayugo, J.A. and Dávila, C.G. A continuum damage model for composite laminates: part II - computational implementation and validation. Mechanics of Materials. 2006; submitted for publication.

[41] Joffe, R., Krasnikovs, A. and Varna, J. COD-based simulation of transverse cracking and stiffness reduction in (S/90n)s laminates. Composites Science and Technology. 2001; 61:637-656.

[42] Bažant, Z.P. and Oh, B.H. Crack band theory for fracture of concrete. Matériaux et Constructions. 1983; 16(93):155-177.

[43] Bažant, Z.P. and Jirásek, M. Nonlocal integral formulations of plasticity and damage: survey of progress. Journal of Engineering Mechanics. 2002; 128:11191149 .

[44] Maimí, P. Modelización constitutiva y computacional del daño y la fractura de materiales compuestos. 2006; Ph.D Thesis. Universitat de Girona, Spain.

[45] ABAQUS 6.5 User's Manual, ABAQUS Inc., Pawtucket, RI, U.S.A. (2005).

[46] Dávila, C.G., Turon, A. and Camanho, P.P., Decohesion elements for shell analysis, Proccedings of the Composites Testing and Model Identification Conference, P.P. Camanho, M.R. Wisnom and F. Pierron, eds., Porto, Portugal, 10-12 April 2006. 


\section{List of Figures}

$1 \quad$ Position of strain gages.

2 Applied load and AE signals as a function of time for the specimen with a $6 \mathrm{~mm}$ diameter hole.

3 Net-section tension failures in specimens with $w / d=6$.

4 Relation between remote stress and longitudinal strain in SG3. 28

$5 \quad$ Cohesive crack constitutive law and fracture process zone. 29

$6 \quad$ Fracture surfaces and corresponding internal variables. 30

$7 \quad$ Scaling of constitutive model for different element sizes. 31

$8 \quad$ Different mesh refinements: a) mesh 1; b) mesh 2

9 Load-displacement relation predicted using the model proposed.

10 Load-displacement relation predicted using the non-adjusted model.

11 Evolution of fiber fracture in the top $0^{\circ}$ ply for the specimen OHT9.

12 Experimental and numerical results- specimen OHT6, strain gages SG2 and SG3.

13 Predictions of size effects in CFRP plates with $w / d=6$. 


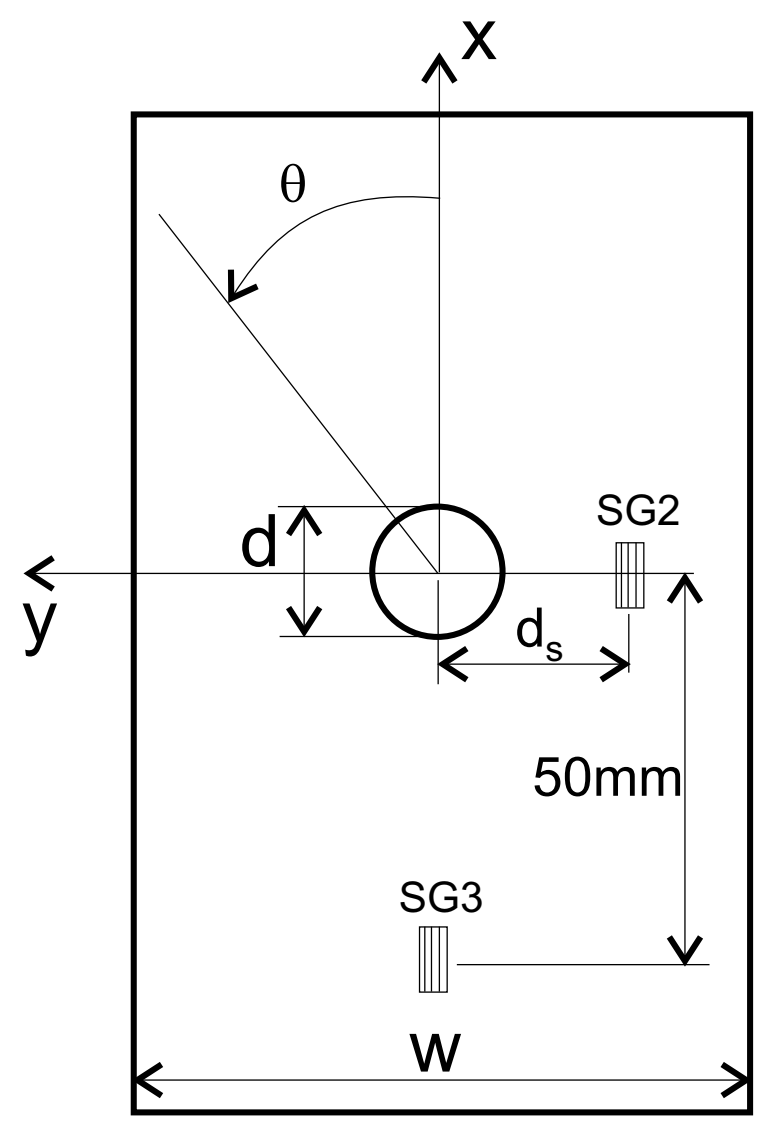

Fig. 1. Position of strain gages. 


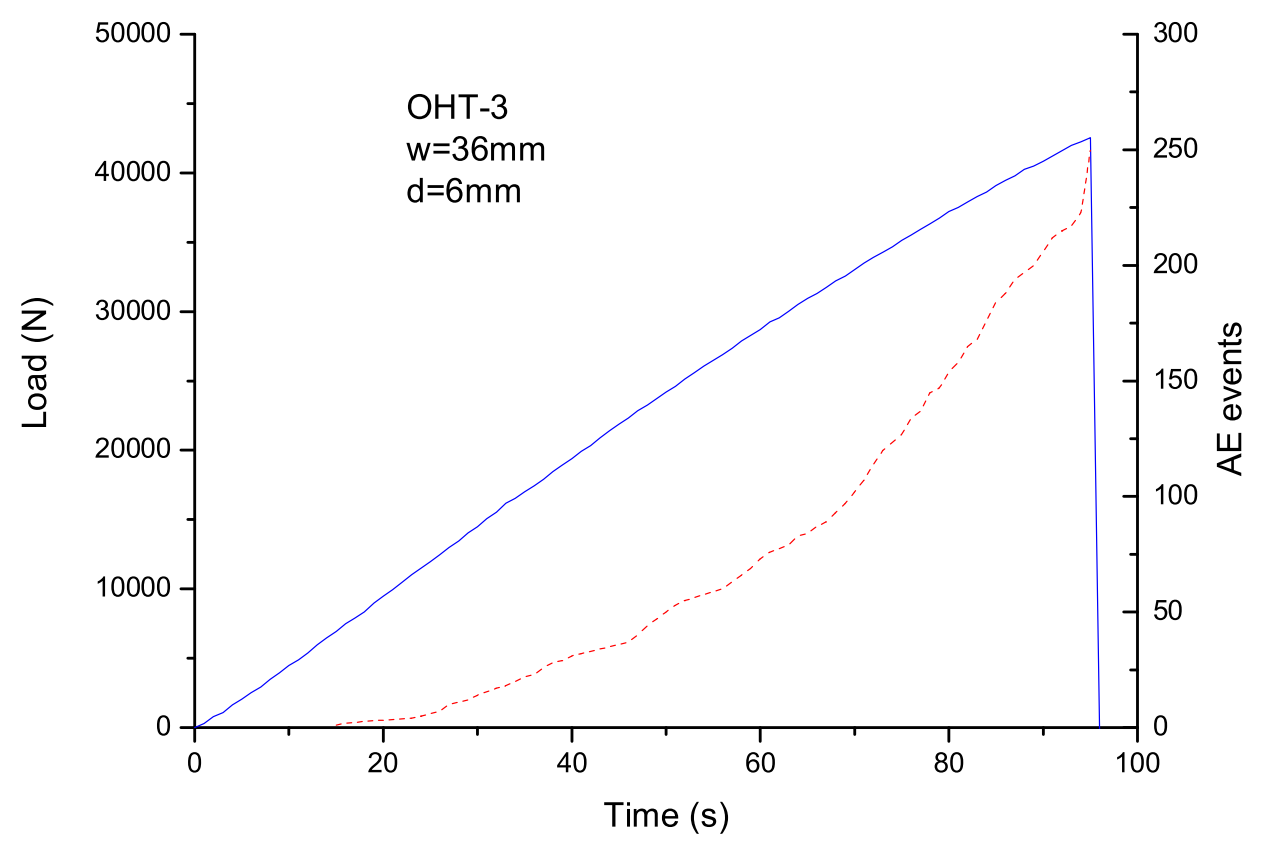

Fig. 2. Applied load and AE signals as a function of time for the specimen with a $6 \mathrm{~mm}$ diameter hole. 


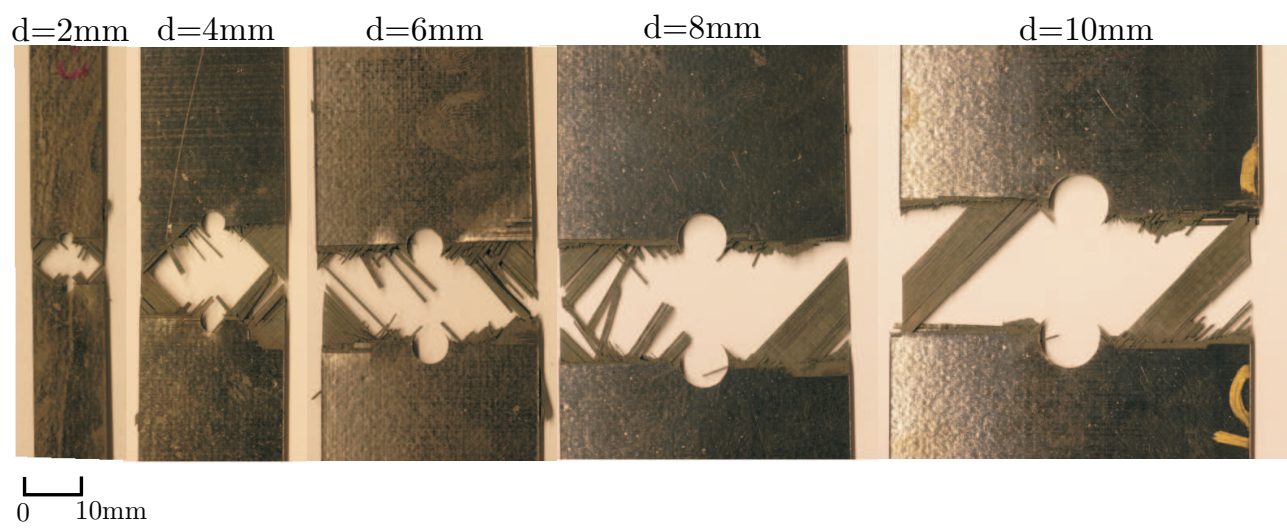

Fig. 3. Net-section tension failures in specimens with $w / d=6$. 


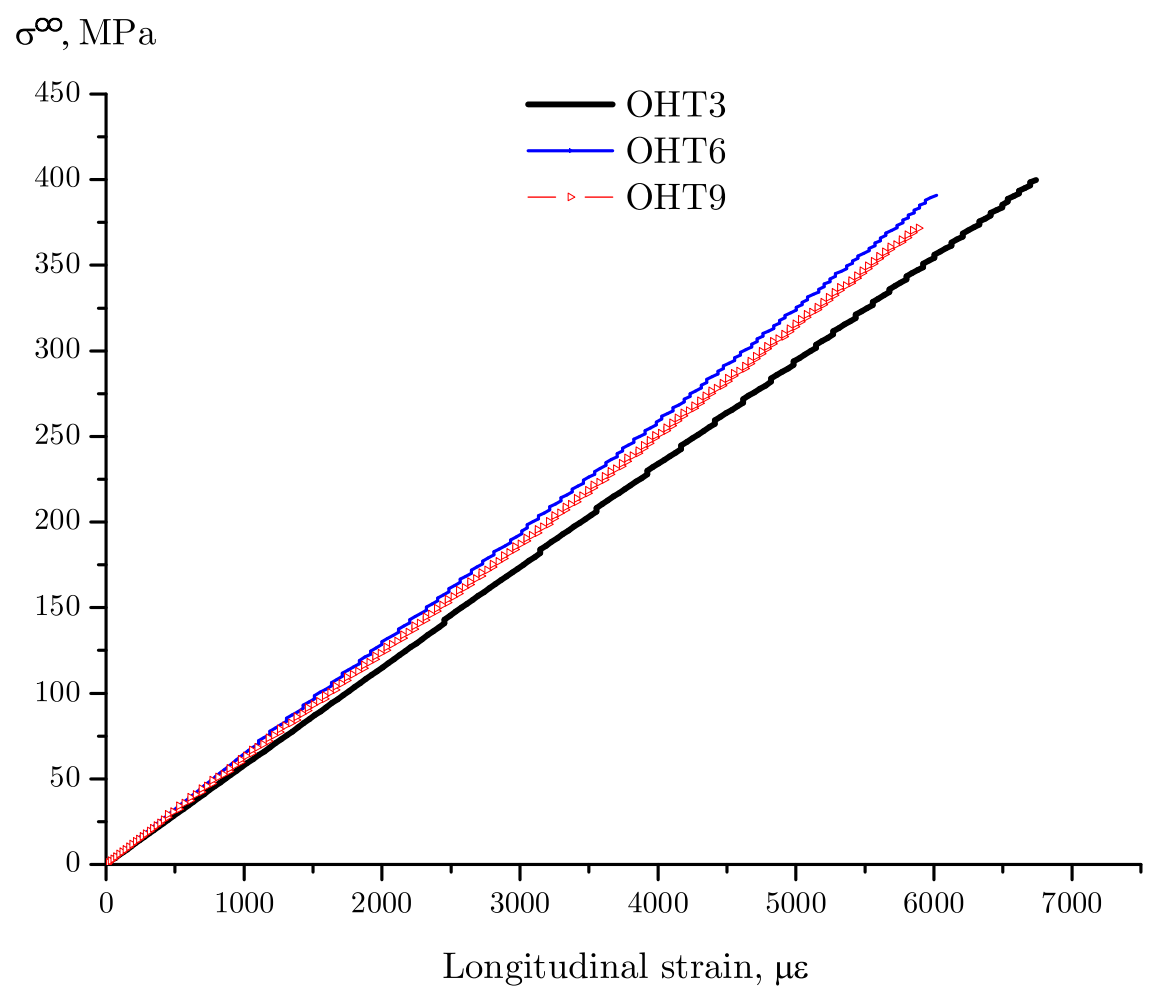

Fig. 4. Relation between remote stress and longitudinal strain in SG3. 


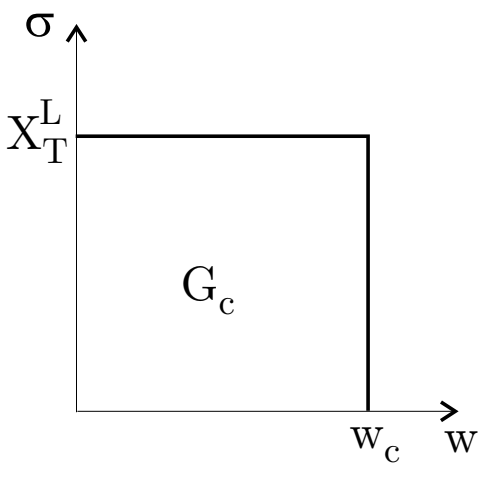

a) Constitutive model
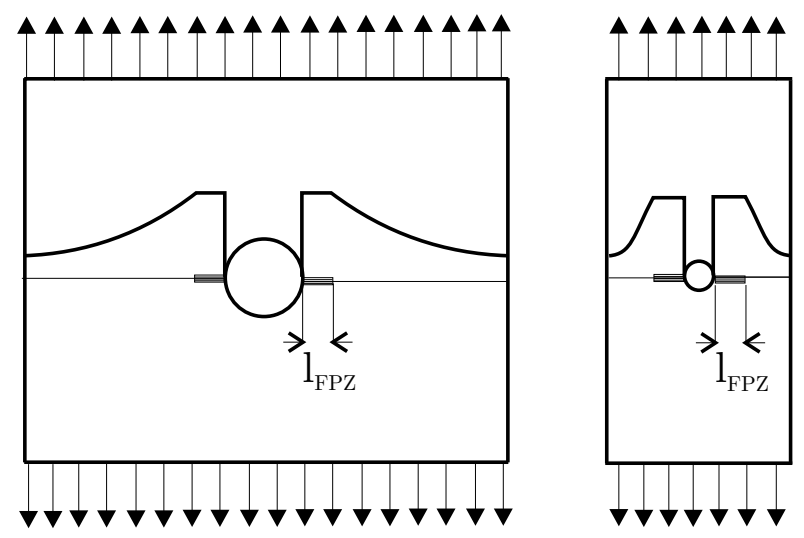

b) Stress distributions along the fracture plane

Fig. 5. Cohesive crack constitutive law and fracture process zone. 


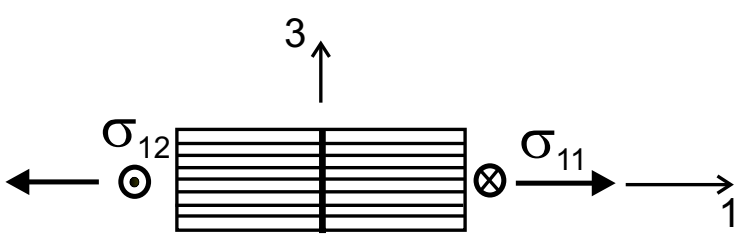

$r_{1+}$

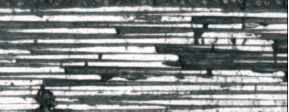

a) Longitudinal tensile fracture

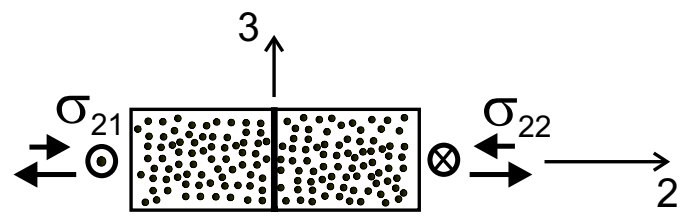

$r_{2+}$

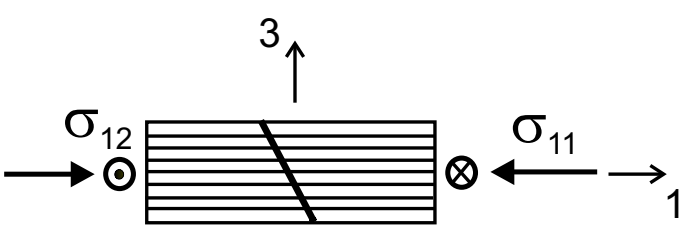

$r_{1-}$

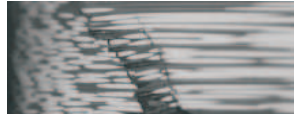

b) Longitudinal compressive fracture

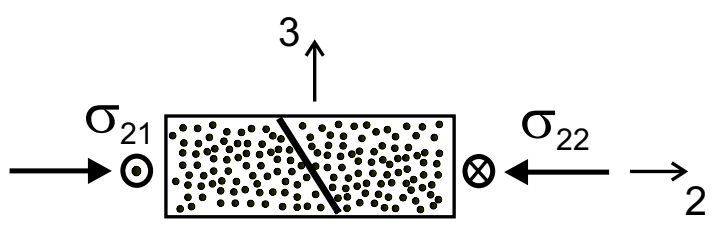

$r_{2-}$

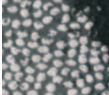

d) Transverse fracture with $\alpha=53^{\circ}$

c) Transverse fracture with $\alpha=0^{\circ}$

Fig. 6. Fracture surfaces and corresponding internal variables. 


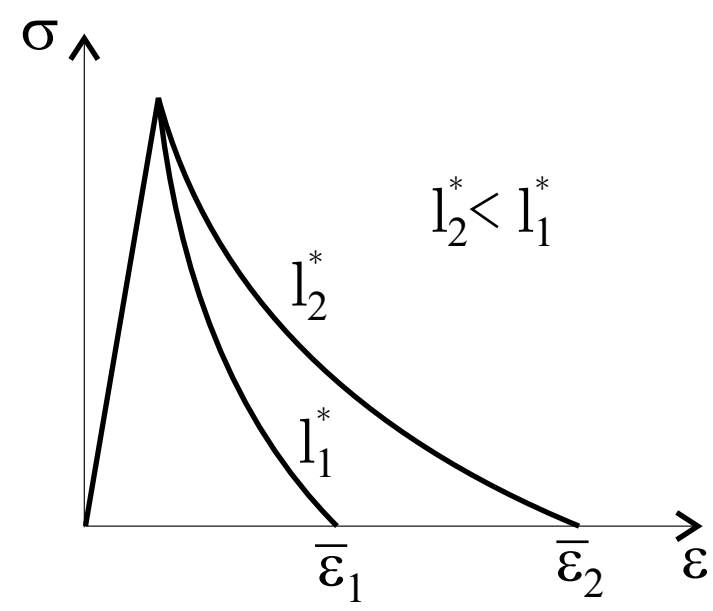

Fig. 7. Scaling of constitutive model for different element sizes. 
a)

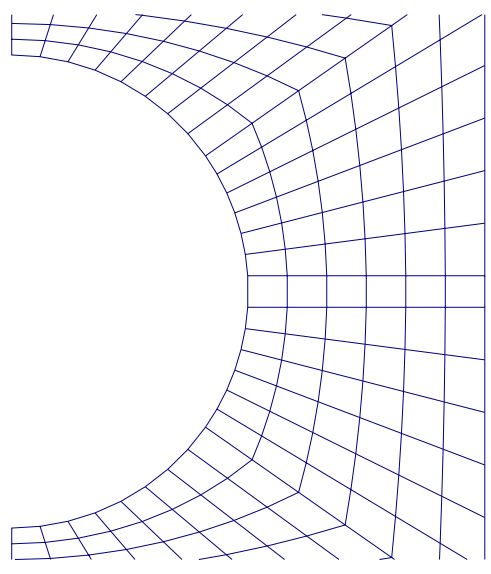

b)

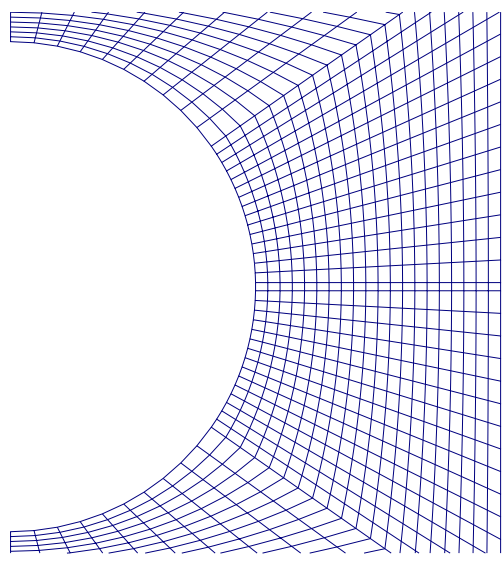

Fig. 8. Different mesh refinements: a) mesh 1; b) mesh 2 


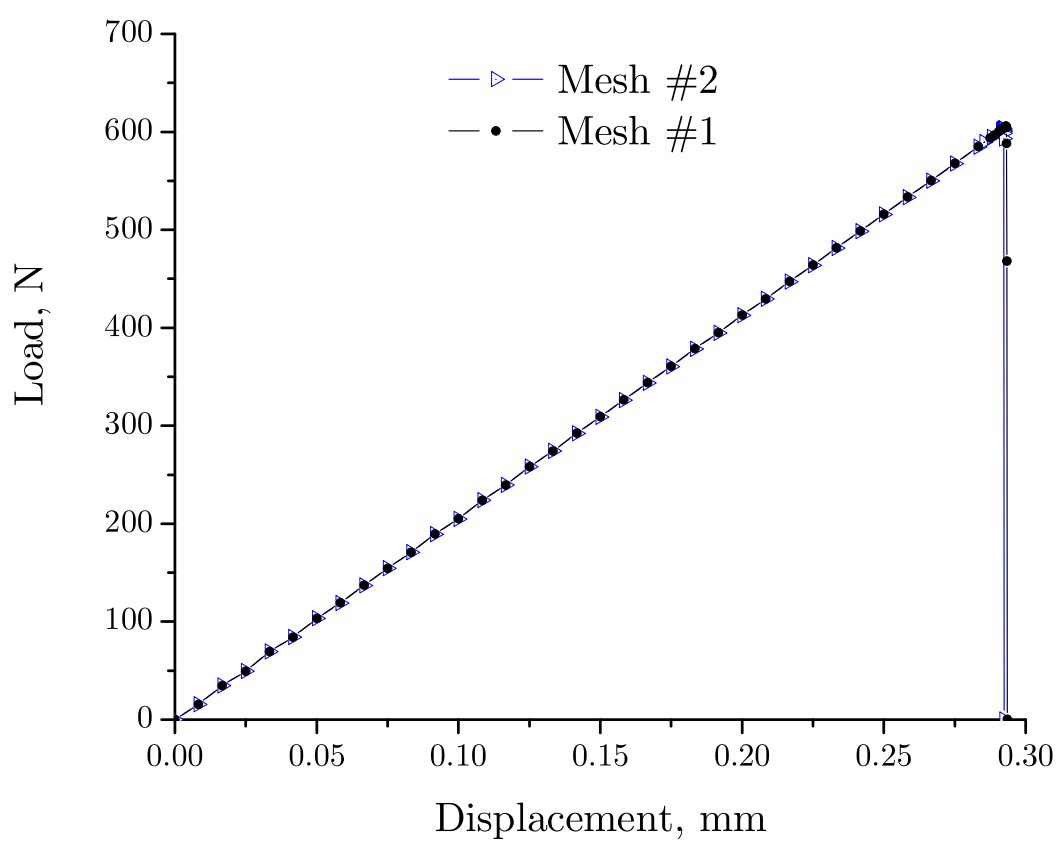

Fig. 9. Load-displacement relation predicted using the model proposed. 


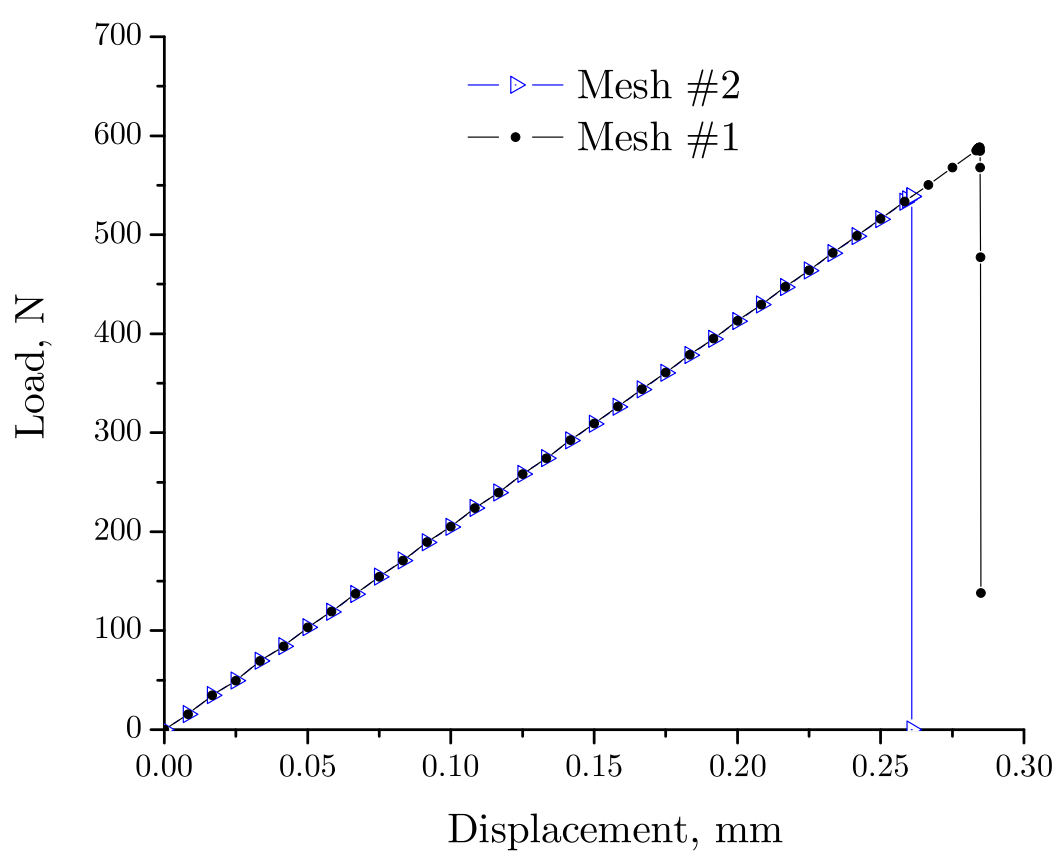

Fig. 10. Load-displacement relation predicted using the non-adjusted model. 

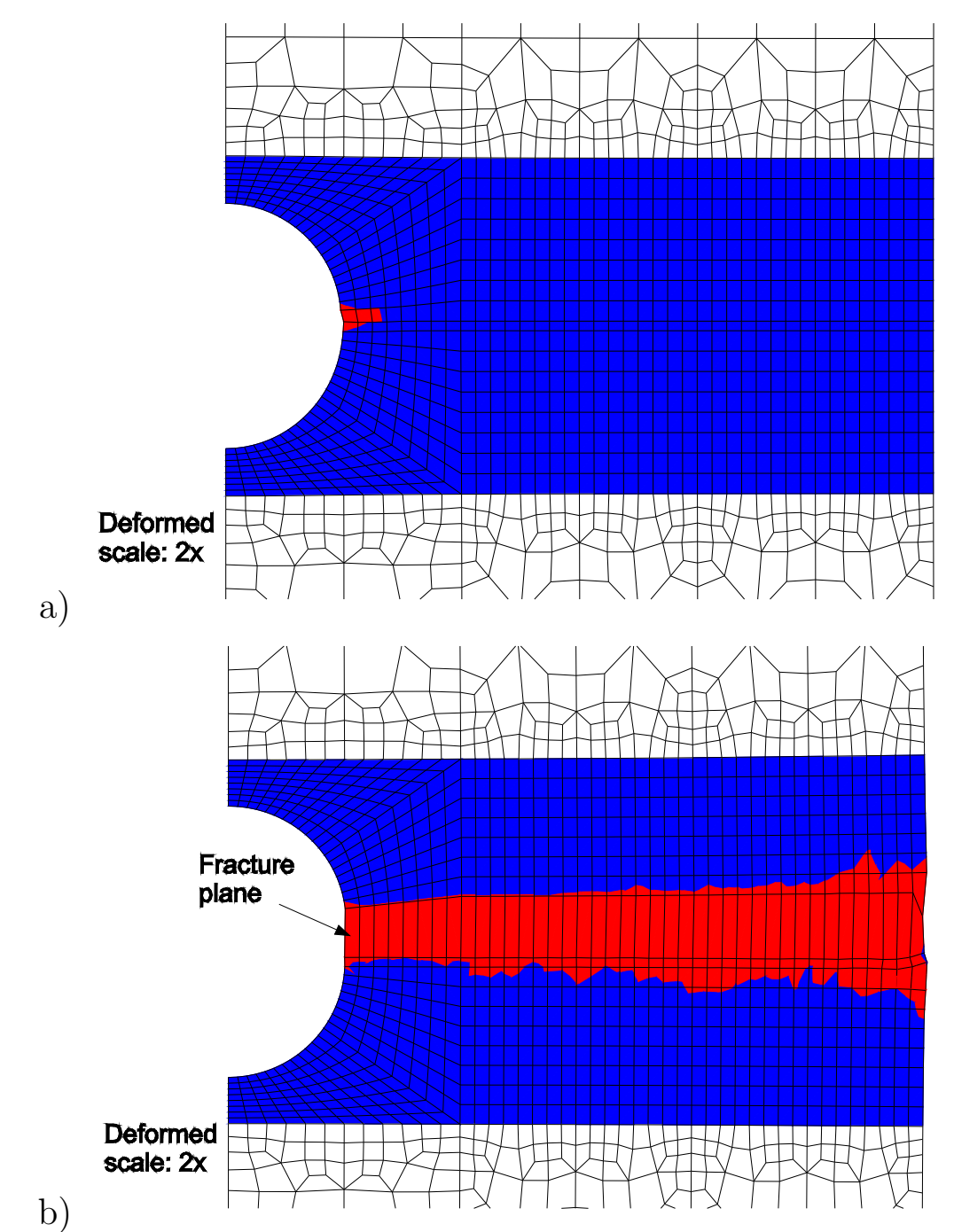

Fig. 11. Evolution of fiber fracture in the top $0^{\circ}$ ply for the specimen OHT9. 


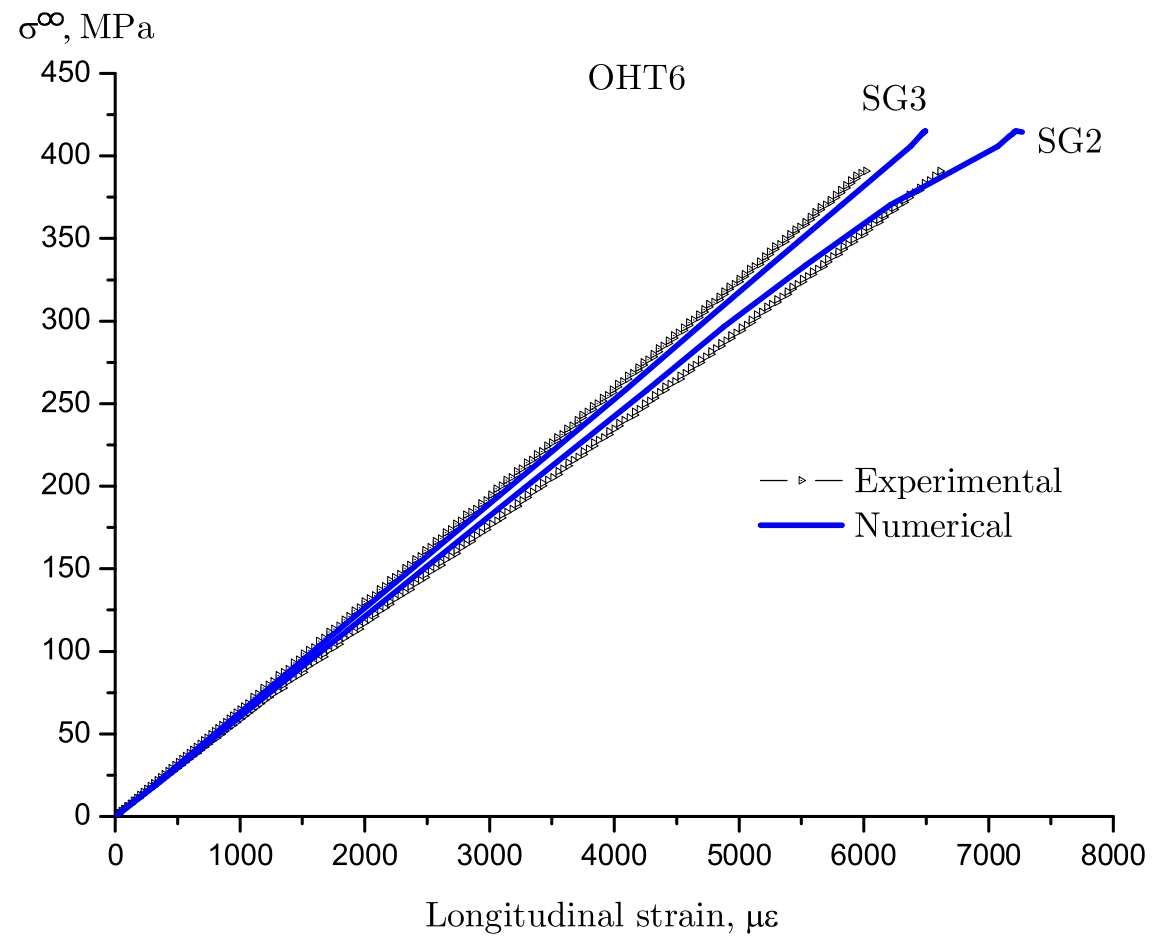

Fig. 12. Experimental and numerical results- specimen OHT6, strain gages SG2 and SG3. 


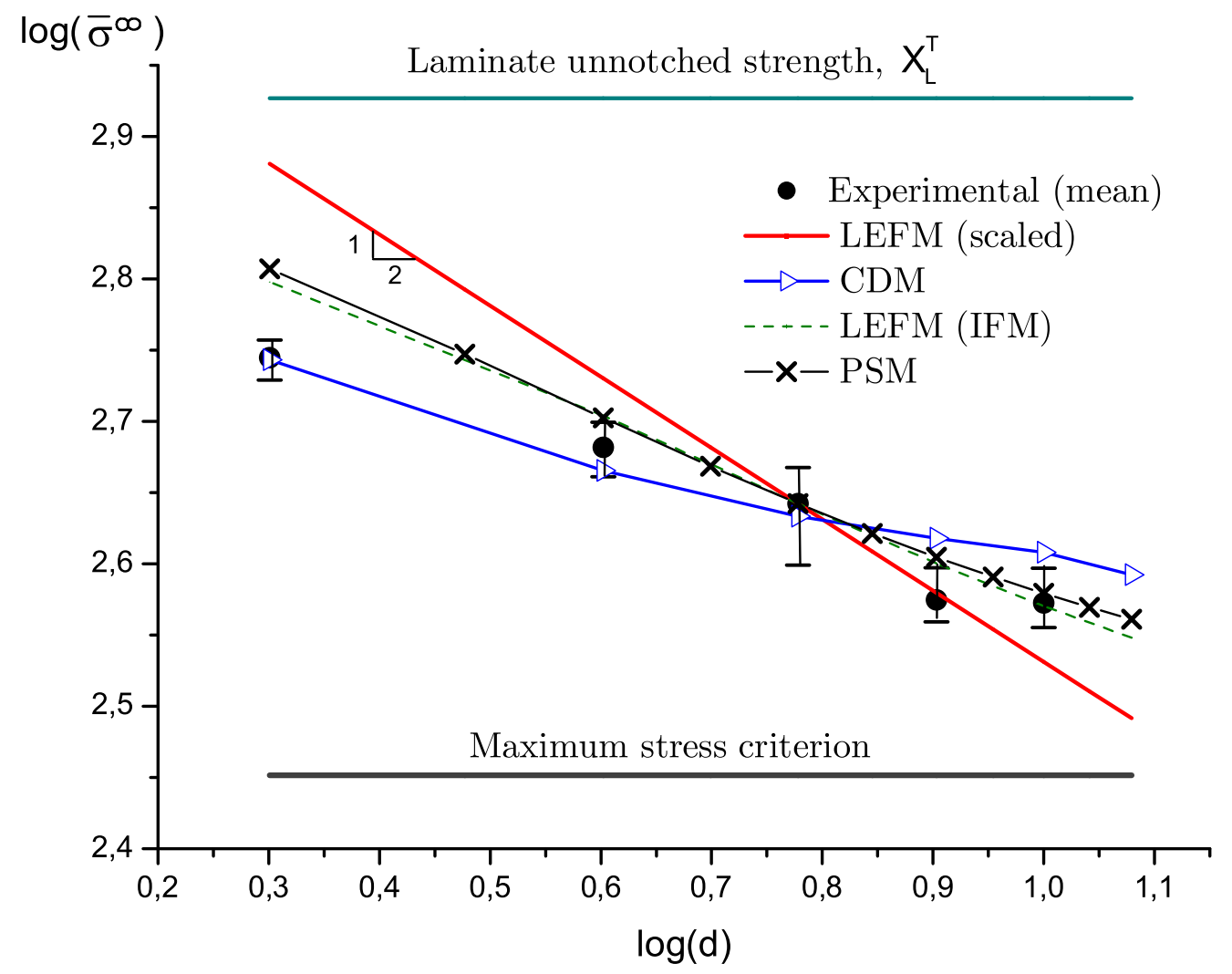

Fig. 13. Predictions of size effects in CFRP plates with $w / d=6$. 


\section{List of Tables}

$1 \quad$ Measured ply elastic properties for IM7-8552. 39

$2 \quad$ Measured ply strengths for IM7-8552. 40

3 Measured fracture energies for transverse fracture for IM7-8552 $\left(\mathrm{kJ} / \mathrm{m}^{2}\right)$.

4 Calculated in-situ strengths for IM7-8552 (MPa).

$5 \quad$ Fracture energies for longitudinal fracture for IM7-8552 $\left(\mathrm{kJ} / \mathrm{m}^{2}\right)$.

$6 \quad$ Open hole tension test matrix. 44

$7 \quad$ Results of open-hole tensile tests. $\quad 45$

8 Comparison between experimental and numerical failure stresses (MPa). 
Table 1

Measured ply elastic properties for IM7-8552.

\begin{tabular}{lllll}
\hline \hline Property & Standard & Mean value & STDV & CV (\%) \\
\hline$E_{1}(\mathrm{GPa})$ & Ref. [20] & 171.42 & 2.38 & 1.39 \\
$E_{2}(\mathrm{GPa})$ & Ref. [20] & 9.08 & 0.09 & 1.03 \\
$G_{12}(\mathrm{GPa})$ & Ref. [22] & 5.29 & 0.13 & 2.53 \\
$v_{12}$ & Ref. [20] & 0.32 & 0.02 & 6.18 \\
\hline \hline
\end{tabular}


Table 2

Measured ply strengths for IM7-8552.

\begin{tabular}{lllll}
\hline \hline Property & Standard & Mean value (MPa) & STDV (MPa) & CV (\%) \\
\hline$X_{\mathrm{T}}$ & Ref. [20] & 2326.2 & 134.1 & 5.8 \\
$X_{\mathrm{C}}$ & Ref. [21] & 1200.1 & 145.7 & 12.1 \\
$Y_{\mathrm{T}}^{\mathrm{ud}}$ & Ref. [20] & 62.3 & 5.3 & 8.5 \\
$Y_{\mathrm{C}}$ & Ref. [21] & 199.8 & 20.5 & 10.2 \\
$S_{\mathrm{L}}^{\mathrm{ud}}$ & Ref. [22] & 92.3 & 0.6 & 0.7 \\
\hline \hline
\end{tabular}


Table 3

Measured fracture energies for transverse fracture for IM7-8552 $\left(\mathrm{kJ} / \mathrm{m}^{2}\right)$.

\begin{tabular}{llll}
\hline \hline Property & Mean value & STDV & CV (\%) \\
\hline $\mathrm{G}_{2+}$ & 0.2774 & 0.0246 & 0.88 \\
$\mathrm{G}_{6}$ & 0.7879 & 0.0803 & 10.19 \\
\hline \hline
\end{tabular}


Table 4

Calculated in-situ strengths for IM7-8552 (MPa).

\begin{tabular}{lll}
\hline Ply configuration & $Y_{T}$ & $S_{L}$ \\
\hline Thin embedded ply & 160.2 & 130.2 \\
Thin outer ply & 101.4 & 107.0 \\
\hline \hline
\end{tabular}


Table 5

Fracture energies for longitudinal fracture for IM7-8552 (kJ/m²).

\begin{tabular}{llll}
\hline \hline Property & Mean value & STDV & CV $(\%)$ \\
\hline $\mathrm{G}_{1+}$ & 81.5 & 6.1 & 7.6 \\
$\mathrm{G}_{1-}$ & 106.3 & 2.2 & 2.1 \\
\hline \hline
\end{tabular}


Table 6

Open hole tension test matrix.

\begin{tabular}{llll}
\hline \hline Specimen ref. & $\mathrm{d}(\mathrm{mm})$ & $\mathrm{w}(\mathrm{mm})$ & $\mathrm{w} / \mathrm{d}$ \\
\hline OHT11 & 2 & 12 & 6 \\
OHT10 & 4 & 24 & 6 \\
OHT3 & 6 & 36 & 6 \\
OHT6 & 8 & 48 & 6 \\
OHT9 & 10 & 60 & 6 \\
\hline \hline
\end{tabular}


Table 7

Results of open-hole tensile tests.

\begin{tabular}{cccc}
\hline \hline Hole diameter $(\mathrm{mm})$ & $\bar{\sigma}^{\infty}(\mathrm{MPa})$ & $\mathrm{STDV}(\mathrm{MPa})$ & $\mathrm{CV}(\%)$ \\
\hline 2 & 555.7 & 15.3 & 2.8 \\
4 & 480.6 & 21.4 & 4.5 \\
6 & 438.7 & 25.3 & 5.8 \\
8 & 375.7 & 15.1 & 4.0 \\
10 & 373.7 & 14.1 & 3.8 \\
\hline \hline
\end{tabular}


Table 8

Comparison between experimental and numerical failure stresses (MPa).

\begin{tabular}{cccc}
\hline Hole diameter $(\mathrm{mm})$ & $\bar{\sigma}^{\infty}$, Experimental & $\bar{\sigma}^{\infty}$, Numerical & Error $(\%)$ \\
\hline 2 & 555.7 & 553.6 & -0.4 \\
4 & 480.6 & 463.0 & -3.7 \\
6 & 438.7 & 430.0 & -2.0 \\
8 & 375.7 & 415.0 & +10.5 \\
10 & 373.7 & 405.6 & +8.5 \\
\hline \hline
\end{tabular}

